\title{
Neurotoxin Botulinum Inserts Apoptotic Effects on Certain Cancer Cell Lines Via Neural Niche of Tumors: A Molecular Study
}

\author{
Mona Farhadi ${ }^{\circledR}$, Melikasadat Jameie ${ }^{2,3}{ }^{\circledR}$, Bahareh Derakhshanmehr ${ }^{1}$, Moghadam Tahmasebi', Maryam \\ Soleimani ${ }^{4}$ Seyed Behnamedin Jameie ${ }^{2,5 *(\mathbb{D}}$ \\ 'Department of Microbiology, Karaj Branch, Islamic Azad University, Karaj, Iran. \\ ${ }^{2}$ Neuroscience Research Center, Iran University of Medical Sciences, Tehran, Iran. \\ ${ }^{3}$ Department of Anatomy, Faculty of Medicine, Shahid Beheshti University of Medical Sciences, Tehran, Iran. \\ ${ }^{4}$ Department of Basic Sciences, University of Social Welfare and Rehabilitation, Sciences, Tehran, Iran. \\ ${ }^{5}$ Department of Medical Basic Sciences, Faculty of Allied Medicine, Iran University of Medical Sciences, Tehran, Iran.
}

\begin{abstract}
Background: Background: Botulinum toxin A (BtxA) is a powerful neurotoxin reported to be effective as a cancer adjuvant therapy with fewer side effects. Previously we showed the apoptotic effects of BtxA on the GBM cell line (U87-MG). In order to confirm the positive neurotoxicity of BtxA on other cancer cell lines, including SK-OV-3, CHO, MCF-7, and PC-3, the present research has designed. Methods: The cell lines prepared, cultured, and exposed to different concentrations of BtxA for 24 and 48 hours. Using MTT, Annexin V/PI assays and western blotting, cell viability, and apoptosis studied.

Results: Our results showed that different BtxA Botox concentrations led to significant cell death in each cell line in a dose-dependent manner $(P<0.001)$ but did not for PC-3 cells. The results of the Annexin V/PI staining indicated that BtxA induced apoptosis after 24 hours. The $1.45 \mathrm{U}, 1.75 \mathrm{U}$, and $1.65 \mathrm{U}$ of BtxA respectively induced more than $50 \%$ apoptosis in MCF 7, SK-OV-3, and CHO cell lines. The results of caspase 3 showed more protein expression in the treated group compares to the control group.

Conclusion: BtxA, as a neurotoxin, can insert therapeutic anti-cancer and apoptotic effects on various types of cancerous cells; further studies need to illuminate the possible mechanisms.

Keywords: BtxA neurotoxicity, Apoptosis, MCF-7, PC-3, SK-OV3, CHO cell lines
\end{abstract}

\author{
*Correspondence to \\ Seyed Behnamedin Jameie, \\ Neuroscience Research Center, \\ Iran University of Medical \\ Sciences, Tehran, Iran \\ Email: jameie.sb@iums.ac.ir \\ \& behjame@gmail.com
}

Published online 28 September, 2020

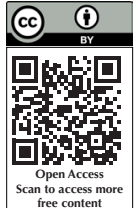

Citation: Farhadi M, Jameie M, Derakhshanmehr B, Tahmasebi M, Soleimani M, Jameie SB. Neurotoxin Botulinum Inserts Apoptotic Effects on Certain Cancer Cell Lines Via Neural Niche of Tumors: A Molecular Study. Clin Neurosci J. 2020;7(4):190-195. doi:10.34172/ icnj.2020.24.

\section{Introduction}

Clostridium, especially Clostridium botulinum, produce botulinum toxin $\mathrm{A}$ (BtxA). BtxA is the strongest biological neurotoxin known to human beings. ${ }^{1}$ Many studies showed that subcutaneous injection of BtxA into the muscle leads to flaccid paralysis via blocking the neuromuscular junction. ${ }^{2}$ Therefore, this neurotoxin has widely used to relieve neurological symptoms such as muscle spasm and reduce pain and motor disorders. In recent years, therapeutic and experimental evidence emerged about the mechanisms of the BtxA as a neurotoxin. It has shown that BtxA not only affects the peripheral nervous system but also affect the central nervous system too. In fact, the toxins are produced as pro-toxins and activated by proteolytic cleavage into disulfide bond-linked chains consisting of $100-\mathrm{kDa}$ heavy chain $(\mathrm{HC})$ and $50-\mathrm{kDa}$ light chain (LC). The HC of BtxA neurotoxin binds to the presynaptic receptors exposed during vesicle recycling. The terminal carboxyl of Hc binds to specific gangliosides and proteins associated with the vesicle membrane (Syt and SV2 isoforms). ${ }^{3}$

In addition to inhibiting nerve cells, BtxA is capable of inducing apoptosis in many cancerous cells. For example, ovarian cancers are among the most common female genital tract cancers, and it has the worst prognosis, and it is currently in the 7 th grade of mortality. ${ }^{4,5}$ Breast and prostate cancers are the most common cancers after lung cancer. The incidence of breast cancer accounts for about one-third of all cancers in women with an increasing trend among Iranian women. Concerning increased age and population in Iran, the rate of cancer cases has expected to increase in the coming years. ${ }^{6}$ Breast cancer is a heterogeneous disease in gene expression, morphology, clinical course, and response to treatment. Common

(C) 2020 The Author(s). This is an open access article distributed under the terms of the Creative Commons Attribution License (http:// creativecommons.org/licenses/by/4.0/), which permits unrestricted use, distribution, and reproduction in any medium, provided the original work is properly cited. 
breast cancer treatments include surgery, chemotherapy, radiotherapy, hormone therapy, or targeted therapy. ${ }^{6}$

On the other hand, prostate cancer is also the second leading cause of death in men worldwide and the eighth cause of cancer death in Iran. However, the most commonly applied prostate cancer treatments are radical prostatectomy, external radiation therapy, and brachytherapy. ${ }^{7,8}$ Despite many efforts that have put in the treatment of these mentioned cancers, their mortality rate remains high. According to the literature, the interest in using BtxA for some type of cancer has increased. Several studies conducted on the therapeutic effects of BtxA, anticancer effects of which have been evaluated in vivo and in vitro.

Coarfa et al demonstrate that nerves play a role in the homeostasis of normal epithelial tissues and are involved in prostate cancer tumor survival. They emphasized that the cross-talk between cancerous cells and the neural microenvironment surrounding them play an important role in disease progression and may make a significant impact in general cancer treatment strategies, as nerve/ cancer interactions are likely important in other cancers as well. Targeting neural microenvironment may represent a therapeutic approach to treating human prostate cancer. ${ }^{9}$ In vitro and in vivo induction of apoptosis of the human prostate cancer LNCaP and PC-3 cell lines by BtxA in a dose-dependent manner reported recently. ${ }^{10}$ Also, in 2015 a study by Bandala et al on 3T3 cell lines showed that Botox's effect in a dose-dependent manner inhibits growth and causes cell death. ${ }^{11}$ In 2012, Gorgal et al used BtxA as a new treatment for benign prostatic hyperplasia to examine apoptosis regulatory proteins' expression in the rat prostate after the injection of this compound. ${ }^{12}$ Gabriel et al, in 2015, studied the role of BtxA in postmastectomy breast reconstruction and suggested the antinociceptive effects of BtxA and its potential benefits in reducing postoperative pain. ${ }^{13}$ The hypoxia of the tumors is well known as a response to radiation since adequate perfusion is necessary to deliver chemotherapy drugs. Therefore, radiotherapy and chemotherapy that cause transient oxygenation can be used just before cytotoxic therapy. ${ }^{14}$

It had known that radiotherapy and chemotherapy cause complications, such as spastic contraction and painful muscle spasms. BtxA is not only used to treat symptoms associated with cancer itself but also to treat the complications following chemotherapy or radiation therapy. Several studies have shown that BtxA, in addition to its effects on blood supply and neurotransmitters, causes cell death in many cell lines. ${ }^{10,11,15}$

To our knowledge, the effects of BtxA, as a well-known neurotoxin on PC-3 prostate, MCF-7 breast cancer, SK$\mathrm{OV} 3$, and $\mathrm{CHO}$ ovarian cell lines had not studied yet. The present study has designed to find the possible apoptotic effects of BtxA on these cancer cell lines.
Materials and Methods

The present research is an applied experimental cellular and molecular study.

\section{Reagent and Chemical}

SK-OV-3, CHO, MCF-7, and PC-3 cell lines had purchased from the Iran pasture institute. RPMI-1640 (Gibco) and DMEM (Sigma) were purchased. BtxA (Canitox, China) and Annexin V \& PI kit also purchased from Sigma. The antibody of Caspase 3 (Abcam) was purchase.

\section{BtxA Preparation}

In this research, BtxA purchased from Canitox, China. Each vial, containing $100 \mathrm{U}$ (4.8 ng) solvent in sterile saline $9 \%$ and different concentration $(1.35,1.45,1.65$, $1.75,2.25,2.40,2.50)$, was prepared and used in below one hour.

\section{Cell Culture}

The cells were cultured in RPMI-1640 medium culture, 10\% FBS (Gibco), 1\% L glutamine, and 1\% pen/strep. Afterward, the cells incubated at $37^{\circ} \mathrm{C}, 5 \% \mathrm{CO} 2$, and $96 \%$ humidity, followed by their sub-culturing with Trypsin/ EDTA (Sigma). After three subcultures, the obtained product had used for the tests.

\section{Viability Assay}

Cellular metabolic activity evaluated by MTT assay, $2 \times 10^{4}$ cells were transferred into flat 96-well plates and incubated at $37^{\circ} \mathrm{C}$ in a humidified air atmosphere enriched with $5 \%(\mathrm{v} / \mathrm{v}) \mathrm{CO} 2$ for 24 hours to allow the cells attach to the bottom of each well. Botox's various concentrations were treated for all cell lines in triplicate for 24,48 , and 72 hours, respectively. At the end of the treatment, the culture medium was replaced with fresh medium and added to 20 $\mu \mathrm{L}$ of MTT ( $5 \mathrm{mg} / \mathrm{ml}$ in PBS) for four hours. Formosan crystals were formed by mitochondrial reduction of MTT in living cells only and solubilized in DMSO $(200 \mu \mathrm{L} /$ well $)$. Their absorbance was read at $570 \mathrm{~nm}$ after 10 minutes of incubation by an ELISA reader (Bio-Rad, USA).

\section{Annexin V/PI Staining}

The test performed in removable eight-chamber slides (Lab-Tek, Nunc) with 5000 cells/well in triplicate $\left(12 \mathrm{ml} /\right.$ well). The cells have incubated at $37^{\circ} \mathrm{C}$ for 24 , 48 , and 72 hours. Following that, the cells were fixed in methanol-acetone $(\mathrm{V} / \mathrm{V})$ for 10 minutes at $20^{\circ} \mathrm{C}$ and were then incubated with $10 \mathrm{ml}$ Annexin V-FITC (Bender MedSystems, Souffelweyersheim, France) in HEPES buffer $(10 \mathrm{~mm}$ HEPES/NaOH, $150 \mathrm{~mm} \mathrm{NaCl}, 5 \mathrm{~mm}$ $\mathrm{KCl}, 1 \mathrm{~mm} \mathrm{MgCl} 2,1.8 \mathrm{~mm} \mathrm{CaCl}$, all reagents from Sigma) for 15 minutes at $37^{\circ} \mathrm{C}$. They were incubated with PI at $20 \mathrm{mg} / \mathrm{ml}$ in the HEPES buffer for 10 minutes at room temperature in the next stage. The cells have then visualized using an Olympus microscope at $400 \times$ 
magnification using 490-nm and 580-nm emission filters to visualize the green FITC fluorescence and detect the red PI staining, respectively.

\section{PI Staining}

propidium iodide (PI) staining had used to identify the late stage of apoptosis. One million cells per sample fixed in 1 $\mathrm{mL}$ cold ethanol $70 \%$ were added (dropwise) to cell pellet and vortexes (fixed for at least 30 minutes on ice). Ethanolfixed cells were centrifuged, and to ensure that only DNA was stained, the cells treated with $50 \mu \mathrm{L}$ Ribonuclease A. Also, $450 \mu \mathrm{L}$ propidium iodide per one million cells was added directly to cells in RNase A solution. The sample was then incubated for 10-15 minutes and was analyzed by flow cytometry in PI/RNase A.

\section{Blotting Assay}

Western blot analysis has performed as described previously. ${ }^{16}$ Proteins measure with the Bio-Rad protein assay method. Equal amounts of protein were loaded and separated by SDS-poly acrylamide gel (12\%) for electrophoresis and transferred to polyvinylidene fluoride membranes. The protein was extracted from the cell and placed on the SDS-PAGE gel. The SDS PAGE gel used to purify proteins of the cells. The protein was separated on the gel-protein samples and transferred to the polyvinylidene difluoride (PVDF) membrane, and eventually, protein samples, which revealed on the PVDF membrane, were detected using the ECL kit. After blocking with buffer containing 3\% of ECL Advance in $\mathrm{PBS} /$ Tween $0.3 \%$ for 1.5 hours at room temperature, the membrane probed with specific polyclonal antibodies (Abcam) diluted in blocking solution (Caspase3 1:7500, P53 1:7500) antibodies were added to the membrane 1 hour at room temperature. Then, a secondary antibody added onto the membrane. After the incubation time, the secondary antibodies were removed and washed by a trisbuffered saline (TBS) buffer for 3 to 10 minutes

\section{Statistical Analysis}

Data analysis was performed by SPSS version 21, with three replications. The mean \pm SER experimental data were evaluated with one-way ANOVA and Duncan test. $P<0.05$ was considered significant.

\section{Results}

The viability assay results in different concentrations, and time on MCF-7 cells showed decreases in the viability of treated BtxA cells at $1.45 \mathrm{U}$ doses with the $65.45 \%$ cell viability after 24 hours. Data showed a significant decrease in live-cell in all doses at 24 and 48 hours compared to the control group $(P<0.001)$. CHO viability results showed a significant decrease between BtxA treated cells and the control group in 24 hours $(P<0.001)$. The Cell viability percentage was dose-dependent, and the effective concentration in a $\mathrm{CHO}$ cell line was $1.65 \mathrm{U}$ with $56.03 \%$ cell death. Also, in SKOV3 BtxA treated, at $1.75 \mathrm{U}$ caused $59.22 \%$ cytotoxicity after 24 hours; this finding was dosedependent for both cell lines (Figure 1). The PC-3 cell viability results indicated no decrease or cell death in

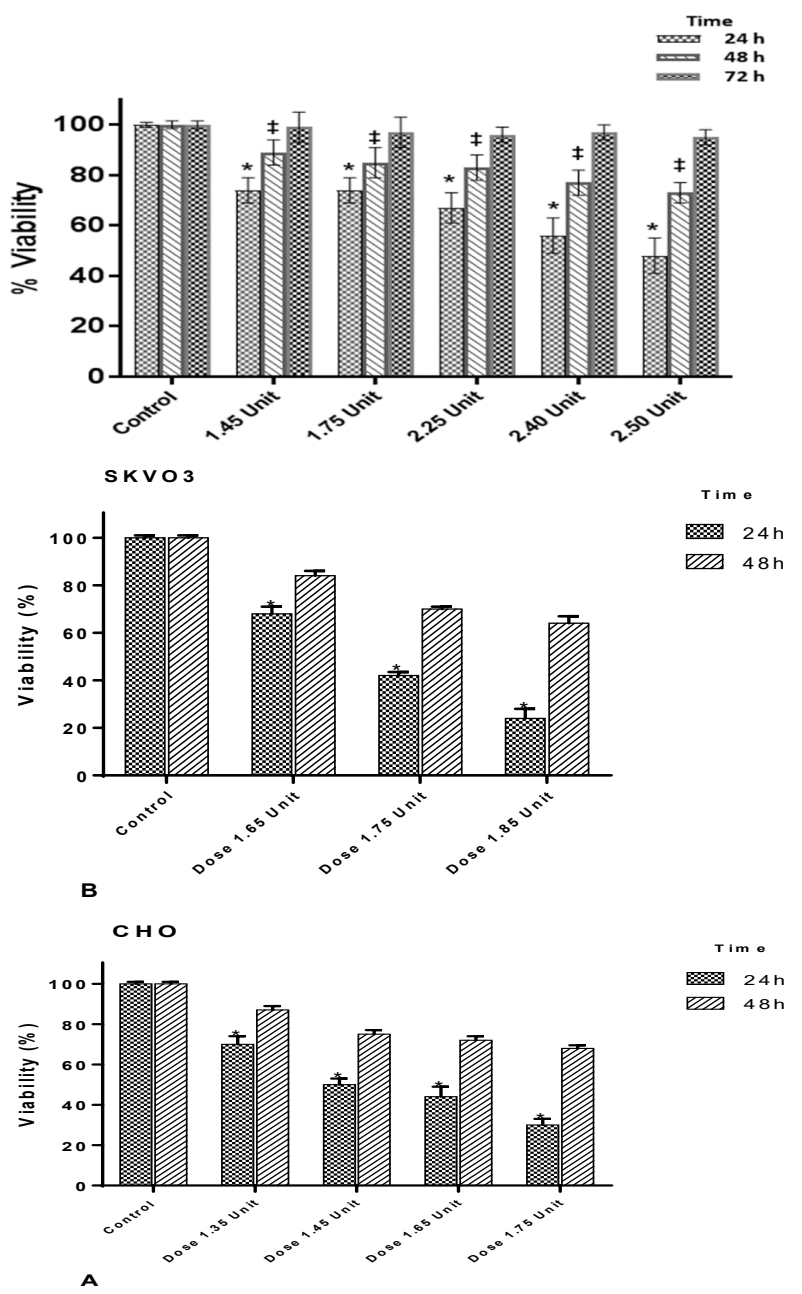

Figure 1. Comparison of Viability Percentage of MCF-7 Cells at Different Times.

Cell viability and mean \pm SER percentage between the control group and the concentrations in $\mathrm{CHO}$ and SK-OV-3 cell lines after 24 and 48 hours $*(P<0.05) . \neq(P<0.05)$ with 72 hours at the same dosage.

Table 1. The Mean Percentage of Viability of PC3 Cells Between Different Concentrations and Times in All Groups

\begin{tabular}{cccccccc}
\hline Botox group & Control & $1.45 \mathrm{U}$ & $1.75 \mathrm{U}$ & $2.25 \mathrm{U}$ & $2.40 \mathrm{U}$ & $2.50 \mathrm{U}$ \\
\hline Live cell\% $24 \mathrm{~h}$ & $95.65 \pm 87.8$ & $89.32 \pm 23.4$ & $80.87 \pm 24.8$ & $90.35 \pm 56.6$ & $93.21 \pm 58.7$ & $80.75 \pm 24.4$ & $83.56 \pm 88.9$ \\
Live cell \% 48h & $93.75 \pm 35.3$ & $89.22 \pm 93.4$ & $88.76 \pm 32.4$ & $91.00 \pm 98.7$ & $95.45 \pm 33.1$ & $88.84 \pm 22.5$ & $83.76 \pm 54.8$ \\
Live cell\% $72 \mathrm{~h}$ & $96.42 \pm 66.8$ & $93.35 \pm 44.5$ & $90.72 \pm 13.5$ & $88.80 \pm 29.5$ & $86.76 \pm 33.5$ & $79.84 \pm 54.6$ & $79.65 \pm 43.6$ \\
\hline
\end{tabular}

MCF7 
different concentrations up to $4.50 \mathrm{U}$ doses and time, and these cells were resistant to the BtxA (Table 1).

The results of PI staining for evaluating the DNA content of all cell lines have shown in Figure 2. Data from all BtxA doses showed a higher presence of necrotic cells after 24 hours. For the MCF-7 cells, $2.50 \mathrm{U}$ of BtxA showed cell death more than $50 \%$, and a significant difference between $2.50 \mathrm{U}$ and other doses within 24 hours observed. In the $\mathrm{CHO}$ and SKOV-3 cells, the percentage of necrosis at $1.75 \mathrm{U}$ was $59.22 \%$ and $72.84 \%$, respectively, after 24 hours, which showed a significant difference compared to the control groups $(P<0.001)$ in 24 hours.

The results of Annexin V \& PI assay revealed that in
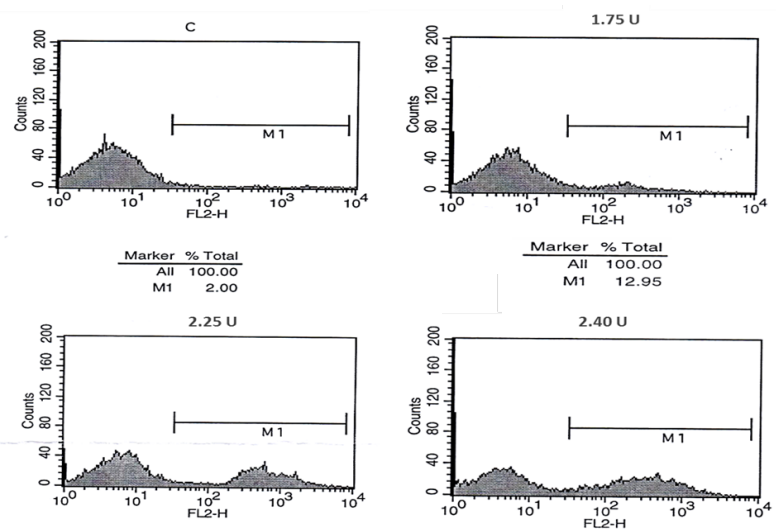

\begin{tabular}{rr} 
Marker $\%$ Total \\
\hline All & 100.00 \\
M1 & 34.75
\end{tabular}
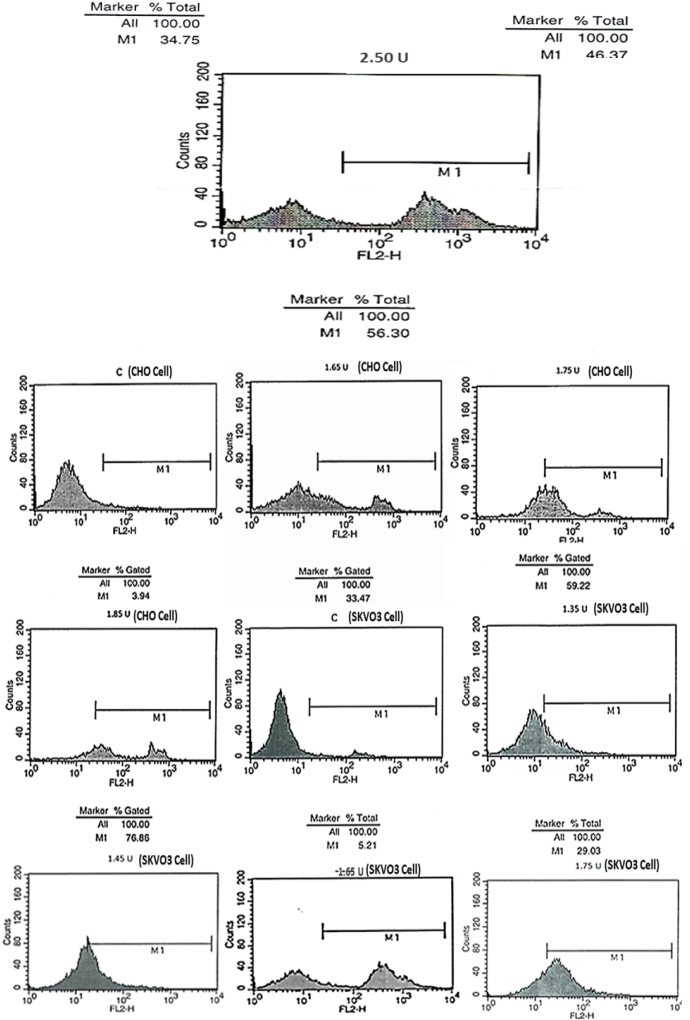

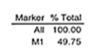

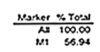

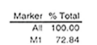

Figure 2. Comparison Necrosis Peak Between Control and BtxA Treated Groups by PI Staining in MCF7, SKOV3, and CHO Cell Lines After 24 Hours.
MCF-7 cells, significant apoptosis and proliferation inhibitory effect induced within 24 hours. Also, at the $2.50 \mathrm{U}$ of BtxA, late and early apoptosis was $14.16 \%$ and $45.45 \%$, respectively, whereas necrosis observes in the PC-3 cell line instead of apoptosis (Figures 3A \& 3B). In two other cell lines, results showed the percentage of annexin $\mathrm{V}$ - positive cells increased. In $\mathrm{CHO}$ cells at the $1.45,1.65$, and 1.75 units and SKOV-3 at the 1.65, 1.75, and 1.85 units of BtxA, significant apoptosis percentage were observed $(P<0.001)$ (Figure $3 \mathrm{C} \& 3 \mathrm{D})$. Comparison apoptosis percentage between different concentrations treated cells and control after 24 and 48 hours in 3 cell lines shown in Figure 4.

Blotting assay results showed increases in the expression of Caspase 3 in treated BtxA group compared to the control group in all cell lines except PC-3 cells after 24 hours (Figure 5).

\section{Discussion}

Cancer is one of the most important health problems in the rrld, and many researchers have put effort into finding a .. satment with minimal side effects and the most efficient results. Breast and prostate cancers are the eighth leading causes of death in Iran. There are different treatments for them, including chemotherapy, radiation therapy, and hormone replacement therapy. While these therapies are available for the mentioned cancers, they are associated with several complications. BtxA, as a neurotoxin, is used in the past for beauty and rejuvenation. Furthermore, it

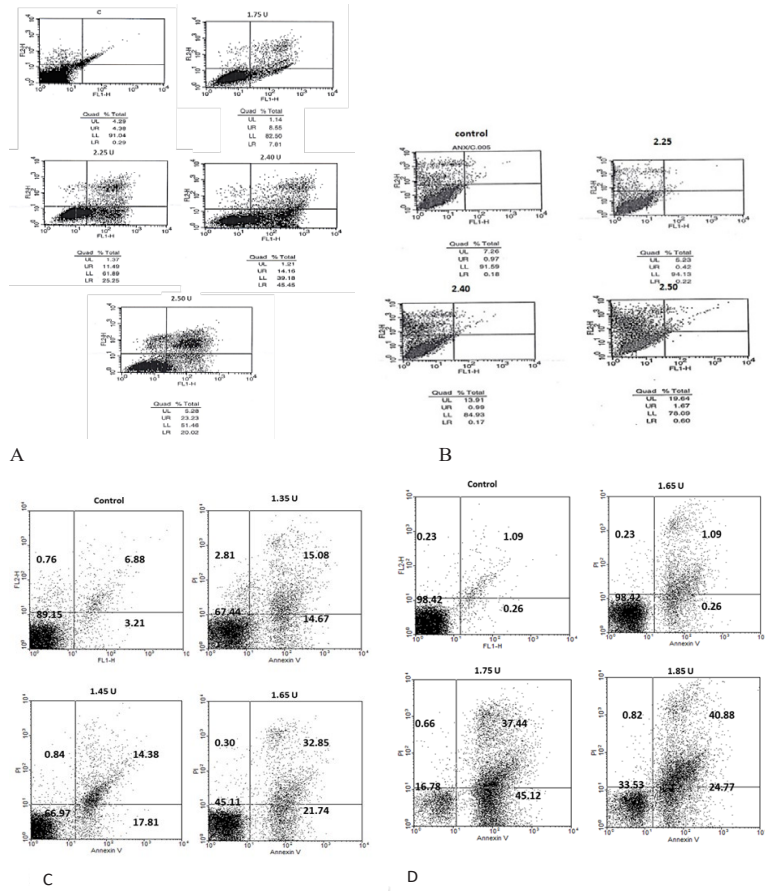

Figure 3. Represented Annexin $\mathrm{V}$ \& $\mathrm{PI}$ Assay Results in $\mathrm{PC}-3$ (A) and MCF-7 (B), SK-OV-3 (C), and CHO (D) BtxA and ControlTreated Cell Lines Groups After 24 Hours Comparison Apoptosis Peak in AnnexinV /PI test 

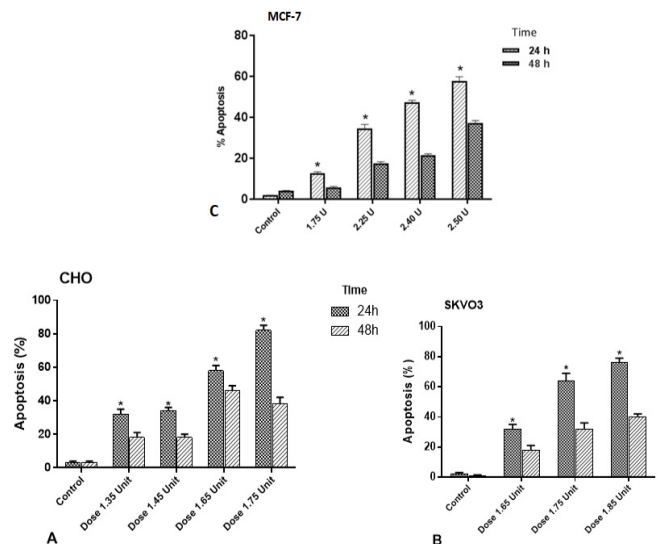

rime
目每
${ }^{24 h}$

Figure 4. MCF- 7, CHO, and SKOV-3 Cells Apoptosis Percent on AnnexinV/PI Test. Mean \pm SER. * Significant difference with the same dose ${ }^{*} \mathrm{P}<0.05$.

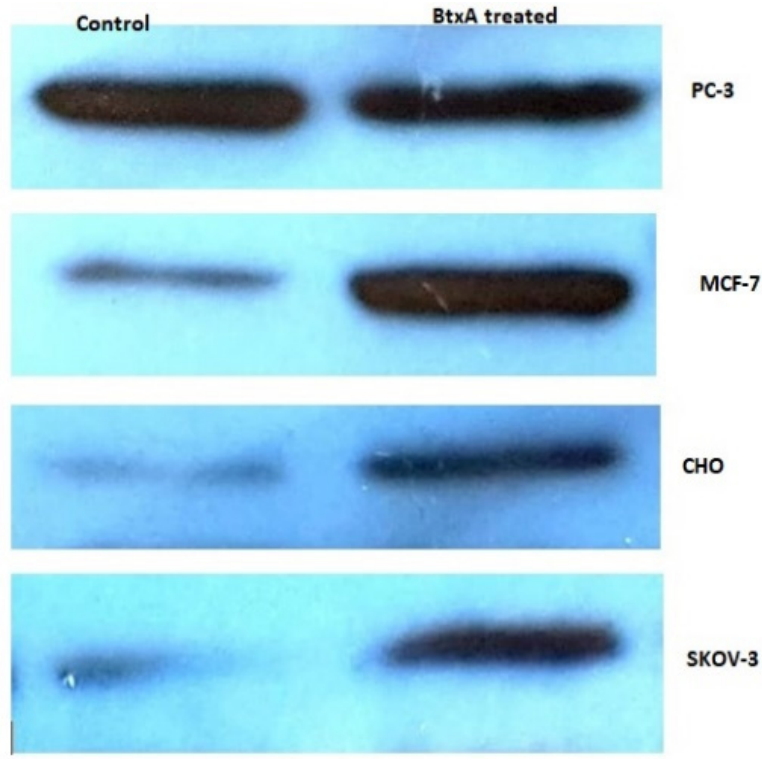

Figure 5. Comparison of the Expression of Caspase 3 in All Cell Lines Between Control and Treated BtxA Groups.

is being used today as medicine and treatment of cancer. Using medicines such as doxorubicin, daunorubicin, bleomycin, and cisplatin is a routine cancer treatment procedure. Nevertheless, they are costly and accompanied by complications, such as bone marrow suppression, anemia, and, most importantly, increased cellular resistance. Therefore, alternative therapies or drugs must be found to overcome these problems.

Ansiaux et al, in 2007, reported that BtxA could use as adjuvant therapy for cancer. In their study also no direct cytotoxic effect was observed when BtxA was incubated directly with tumor cells; therefore, it is unlikely that the inhibition of cell division by BtxA will be enough power to be used alone to treat cancer. They suggested that the benefit from BtxA was directly related to a change in the tumor neuronal microenvironment and not to a direct cytotoxic or radiosensitizing effect. ${ }^{17}$ In 2013 Bandala et al conducted a study to assess the effect of BtxA apoptotic on T47D breast cancer cells and estimated the effect of $0.15 \mathrm{U}$ of BtxA on survival and cell death using MTT and propidium iodide/annexin-V. ${ }^{11}$ BtxA caused a greater cytotoxic activity in T47D cells than normal MCF10A cells, which seemed to induce caspase- 3 and -7 dependent apoptotic processes. The toxicity and apoptosis of BtxA in their study led us to investigate the effect of BtxA on another type of cancer cells. In the present study, we showed BtxA capable of reducing cell viability in a dose-dependent manner and induced apoptosis in three different cancer cell lines. Also, the annexin V/PI results by using flow cytometry confirmed the Botox apoptosis induction. Similar to the results of Bandala et al, our findings demonstrated that those 24 hours were effective inducing apoptosis, and it seems that the MCF-7 cell line had a similar mechanism for responding to BtxA but with the different doses. According to the Bandala et al report, BtxA did not affect the normal MCF10A cell line despite our study for SKOV-3 and $\mathrm{CHO}$ cell lines. Our findings showed the dose and time-dependent effects of BtxA on both different types of cells. Karsenty et al, in 2009, suggested that intraprostatic injection of BtxA improved urinary symptoms associated with benign prostatic hypertrophy $(\mathrm{BPH})$. They showed cell proliferation of PC-3 and LNCaP cell lines compared to the presence and absence of BtxA after four days. Also, the BtxA membrane receptor synaptic protein vesicles 2 (SV2) studied in both cell lines. The results showed that BtxA, in a dosedependent manner, significantly reduced LNCaP cell proliferation and increased apoptosis. However, there was no effect showed on the PC-3 cell line. The SV2 receptor in both cell lines (LNCaP/PC-3) allows the BtxA to penetrate the cell and block cell proliferation factor, so inhibited the growth of human PSA and LNCaP cells in vitro and in vivo. ${ }^{10}$ In the present study, BtxA did not affect the PC-3 cell line at all concentrations and times, even to 72 hours. According to Karsenty et al, PC-3 cells have a lesser SV2 receptor than other types of prostate cancer. Flow cytometry showed significantly increased apoptosis in both cell lines with different doses (SK-OV-3 with $1.75 \mathrm{U}$ and $\mathrm{CHO}$ with $1.65 \mathrm{U}$ ) in a shorter time. ${ }^{10}$ The western blotting results confirmed the apoptotic effects of BtxA with the overexpression of caspase 3. Although BtxA approved to be useful to induce apoptosis for some types of cancer cell lines either in vivo or in vitro research, it has not exactly known why it has no or fewer effects on some other cell line. More research needs to explain the molecular mechanisms for the BtxA effects.

\section{Conclusion}

BtxA, first known for its neurotoxicity on neuromuscular 
junctions, could be supposed as a neurotoxin that acts as an apoptotic inducer with therapeutic effects on cancer cell lines. Although the action mechanisms of BtxA are not exactly known, we believe it may act via the neuronal niche around the tumoral cell. More research needs for a better understanding of BtxA mechanisms on cancer cells.

\section{Conflict of Interest}

The authors declare that they have no conflict of interests.

\section{Acknowledgments}

The Neuroscience Research Center (NRC), Iran University of Medical Science, and Tehran, Iran supported the present study. Now, we extend our gratitude to the colleagues and laboratory staff of NRC for their sincere collaboration.

\section{Authors' Contribution}

$M F, B D, H T$, and $S B J$ were involved in experiments and wrote the paper draft. MS and MJ collected, analyzed the data, prepared and edited the manuscript. All the authors read and approved the final manuscript.

\section{Funding/Support}

The present research has supported the Neuroscience Research Center (NRC) of the Iran University of Medical Science and Islamic Azad University.

\section{Ethical Statement}

The study was conducted by the principles of the Declaration of the Ethical Committee of Iran University of Medical Sciences for Experimental and Cellular research and approved by the Ethical Committee of NRC/IUMS.

\section{Availability of data and materials}

Please contact the author for data requests.

\section{References}

1. Zichel R, Mimran A, Keren A, Barnea A, Steinberger-Levy I, Marcus D, et al. Efficacy of a potential trivalent vaccine based on $\mathrm{Hc}$ fragments of botulinum toxins $\mathrm{A}, \mathrm{B}$, and $\mathrm{E}$ produced in a cell-free expression system. Clin Vaccine Immunol. 2010;17(5):784-92. doi: 10.1128/cvi.00496-09.

2. Peng Chen Z, Morris JG Jr, Rodriguez RL, Wagle Shukla A, Tapia-Núñez J, Okun MS. Emerging opportunities for serotypes of botulinum neurotoxins. Toxins (Basel). 2012;4(11):1196222. doi: 10.3390/toxins4111196.

3. Baldwin MR, Tepp WH, Przedpelski A, Pier CL, Bradshaw M, Johnson EA, et al. Subunit vaccine against the seven serotypes of botulism. Infect Immun. 2008;76(3):1314-8. doi: 10.1128/ iai.01025-07.

4. Piek JM, van Diest PJ, Verheijen RH. Ovarian carcinogenesis: an alternative hypothesis. Adv Exp Med Biol. 2008;622:7987. doi: 10.1007/978-0-387-68969-2_7.

5. Kim A, Ueda Y, Naka T, Enomoto T. Therapeutic strategies in epithelial ovarian cancer. J Exp Clin Cancer Res. 2012;31(1):14. doi: 10.1186/1756-9966-31-14.

6. Arab M, Khayamzadeh M, Mohit M, Hosseini M, Anbiaee $\mathrm{R}$, Tabatabaeefar $\mathrm{M}$, et al. Survival of ovarian cancer in Iran: 2000-2004. Asian Pac J Cancer Prev. 2009;10(4):555-8.

7. Proietti S, Nardicchi V, Porena M, Giannantoni A. [Botulinum toxin type-A toxin activity on prostate cancer cell lines]. Urologia. 2012;79(2):135-41. doi: 10.5301/ru.2012.9254.

8. Truin W, Voogd AC, Vreugdenhil G, van der Heiden-van der Loo M, Siesling S, Roumen RM. Effect of adjuvant chemotherapy in postmenopausal patients with invasive ductal versus lobular breast cancer. Ann Oncol. 2012;23(11):285965. doi: 10.1093/annonc/mds180.

9. Coarfa C, Florentin D, Putluri N, Ding Y, Au J, He D, et al. Influence of the neural microenvironment on prostate cancer. Prostate. 2018;78(2):128-39. doi: 10.1002/pros.23454.

10. Karsenty G, Rocha J, Chevalier S, Scarlata E, Andrieu C, Zouanat $\mathrm{FZ}$, et al. Botulinum toxin type $\mathrm{A}$ inhibits the growth of LNCaP human prostate cancer cells in vitro and in vivo. Prostate. 2009;69(11):1143-50. doi: 10.1002/pros.20958.

11. Bandala C, Cortés-Algara AL, Mejía-Barradas CM, IlizaliturriFlores I, Dominguez-Rubio R, Bazán-Méndez $\mathrm{Cl}$, et al. Botulinum neurotoxin type $A$ inhibits synaptic vesicle 2 expression in breast cancer cell lines. Int J Clin Exp Pathol. 2015;8(7):8411-8.

12. Gorgal T, Charrua A, Silva JF, Avelino A, Dinis P, Cruz F. Expression of apoptosis-regulating genes in the rat prostate following botulinum toxin type A injection. BMC Urol. 2012;12:1. doi: 10.1186/1471-2490-12-1.

13. Gabriel A, Champaneria MC, Maxwell GP. The efficacy of botulinum toxin $\mathrm{A}$ in post-mastectomy breast reconstruction: a pilot study. Aesthet Surg J. 2015;35(4):402-9. doi: 10.1093/ asj/sjv040.

14. Graham K, Unger E. Overcoming tumor hypoxia as a barrier to radiotherapy, chemotherapy and immunotherapy in cancer treatment. Int J Nanomedicine. 2018;13:6049-58. doi: 10.2147/ijn.s140462.

15. Oh SH, Lee Y, Seo YJ, Lee JH, Yang JD, Chung HY, et al. The potential effect of botulinum toxin type $A$ on human dermal fibroblasts: an in vitro study. Dermatol Surg. 2012;38(10):168994. doi: 10.1111/j.1524-4725.2012.02504.x.

16. Arunasree KM. Anti-proliferative effects of carvacrol on a human metastatic breast cancer cell line, MDA-MB 231. Phytomedicine. 2010;17(8-9):581-8. doi: 10.1016/j. phymed.2009.12.008.

17. Ansiaux R, Gallez B. Use of botulinum toxins in cancer therapy. Expert Opin Investig Drugs. 2007;16(2):209-18. doi: 10.1517/13543784.16.2.209. 